\title{
INCIDENCE OF RHEUMATIC FEVER IN CEYLON
}

\author{
BY \\ STANLEY DE SILVA \\ From the Lady Ridgeway Hospital for Children and the Maternity Hospitals of Colombo, Ceylon
}

(RECEIVED FOR PUBLICATION NOVEMBER 19, 1958)

Conflicting views have been expressed about the incidence of rheumatic fever in the tropics. Fernando (1939) concluded that 'rheumatic infection is an important cause of heart disease among the hospital class of the population of Ceylon and accounts for from anything between one-fourth to one-fifth of the total cardiovascular diseases among them. The incidence, manifestations, virulence and progressiveness of rheumatic carditis scarcely differ in any important respects from what is seen in non-tropical countries'.

While this is probably quite true of rheumatic infection in the adult, it was thought fit to investigate its incidence and manifestations in the children in this country.

\section{Incidence}

In studying the incidence of the disease as it occurs in children in Ceylon, I have contrasted the incidence as seen in the Children's Hospital, Colombo, the General Hospital, Colombo, and The Hospital for Sick Children, Great Ormond Street, London. The Lady Ridgeway Hospital for Children (400 beds) is the only hospital for children in Ceylon and admits about 18,000 children up to the age of 12 years annually, with a daily out-patient attendance of about 1,200. It draws its patients mainly from Colombo but also from all parts of the island. The General Hospital (1,500 beds) is for adults only. I have chosen The Hospital for Sick Children, Great Ormond Street, for comparison as it is the largest children's hospital in England and also has about 400 beds.
I shall deal with the incidence of rheumatic fever in the Children's Hospital, Colombo, in the period 1953-57. During this five-year period 70,292 children were admitted to the hospital, and, of these, 560 were admitted for some form of rheumatic disease, an incidence of $0.7 \%$ of the total admissions. Two hundred and two of this group had signs of carditis, i.e. nearly $35 \%$ of those admitted for rheumatic disease and $0.2 \%$ of the total admissions (Table 1).

A more detailed study was made of the incidence in my unit of 75 beds during this period. It was found that out of a total of 13,656 children admitted there were 107 patients $(0 \cdot 78 \%)$ with rheumatic manifestation, and 34 of these children (i.e. $0 \cdot 2 \%$ of the total admissions) showed cardiac manifestations. It will be seen again that in this unit $31 \%$ of the rheumatic children showed evidence of cardiac involvement. The pattern of the disease, in my unit, therefore, is very similar to that seen in the hospital as a whole.

There were 12 deaths due to rheumatic disease during this period, almost every death being due to cardiac disease, a death rate of $2 \%$ amongst those admitted with infection.

When this picture is compared with that seen at the General Hospital, Colombo, during the period 1952-57, out of a total of 355,401 admissions there were 3,538 admissions for rheumatic infection (i.e. $0.7 \%$ of admissions), amongst whom were 2,848 patients with carditis $(0 \cdot 8 \%$ of the total admissions).

TABLE 1

ADMISSIONS TO THE LADY RIDGEWAY HOSPITAL FOR CHILDREN: 1953-57

\begin{tabular}{|c|c|c|c|c|c|c|c|c|c|c|c|c|c|}
\hline \multicolumn{8}{|c|}{ Admissions } & \multirow{2}{*}{$\frac{1953}{10,884}$} & \multirow{2}{*}{$\frac{1954}{12,174}$} & \multirow{2}{*}{$\frac{1955}{14,154}$} & \multirow{2}{*}{$\frac{1956}{16,551}$} & \multirow{2}{*}{$\begin{array}{c}1957 \\
18,529\end{array}$} & \multirow{2}{*}{$\begin{array}{c}\begin{array}{c}\text { Five-year } \\
\text { Total }\end{array} \\
70,292\end{array}$} \\
\hline Total per year & $\ldots$ & . & $\ldots$ & $\ldots$ & . & $\ldots$ & $\cdots$ & & & & & & \\
\hline For rheumatic disease & $\cdots$ & $\cdots$ & $\cdots$ & $\cdots$ & $\cdots$ & . & $\cdots$ & $\begin{array}{c}99 \\
(0.9 \%)\end{array}$ & $\begin{array}{c}88 \\
(0.5 \%)\end{array}$ & $\begin{array}{c}81 \\
0.5 \%)\end{array}$ & $\begin{array}{l}128 \\
(0.8 \%)\end{array}$ & $\begin{array}{l}164 \\
(0.8 \%)\end{array}$ & $\begin{array}{l}560 \\
(0.7 \%)\end{array}$ \\
\hline For carditis .. & $\cdots$ & $\cdots$ & $\cdots$ & $\cdots$ & . & . & $\cdots$ & $\begin{array}{c}33 \\
(0.3 \%)\end{array}$ & $\begin{array}{c}67 \\
(0.4 \%)\end{array}$ & $\begin{array}{c}28 \\
(0.3 \%)\end{array}$ & $\begin{array}{c}41 \\
(0.2 \%)\end{array}$ & $(0.1 \%)$ & $\begin{array}{c}202 \\
(0.2 \%)\end{array}$ \\
\hline \multicolumn{8}{|c|}{ Percentage of carditis among cases admitted for rheumatic infection .. } & $33 \%$ & $76 \%$ & $31 \%$ & $44 \%$ & $51 \%$ & $35 \%$ \\
\hline
\end{tabular}


So, although the incidence of rheumatic infection is nearly the same in the child and in the adult, the incidence of carditis is four times greater in the latter. Further, while 202 children, or only $35 \%$ of the children with rheumatic infection, showed evidence of established cardiac involvement on admission, 2,848 adults, $80 \%$ of the rheumatic patients, showed cardiac involvement (Table 2).

It can therefore be concluded that in the tropics cardiac manifestations are more common in adults or occur at a much later age than in temperate zones.

I have compared these findings with those of Cox and Schlesinger (1955) who analysed the incidence of the disease as seen at The Hospital for Sick Children, Great Ormond Street. In showing a steady decline in the severity of the disease and its incidence in relation to hospital admissions during the last 30 years, they found that in the period 1919-20, out of 2,519 admissions to the hospital, there were 262 patients with rheumatic infection (10.8\% of total admissions) of whom 148 showed evidence of cardiac involvement $(56.5 \%)$. There were 22 deaths, a mortality of $8 \%$. During the period 1946-50, out of 59 patients admitted with rheumatic infection, 35 showed evidence of cardiac involvement $(59 \%)$. The incidence was much less during 1949-50, when, out of 4,917 admissions, only $31(0.6 \%)$ showed evidence of rheumatic disease. In 1957 , out of 19 patients admitted with rheumatic infection, $10(52 \%)$ had evidence of cardiac involvement (Cox and Schlesinger, 1956).

While taking into consideration the marked decline in incidence of rheumatic infection as seen from the admissions to that hospital in recent years, one is struck with the very high incidence of carditis amongst those admitted with rheumatic infection: $56 \%, 59 \%$ and $52 \%$, for the respective periods quoted.
It must be conceded that the pattern of the disease as seen in The Hospital for Sick Children, Great Ormond Street, may not be a true reflection of that seen in England as a whole. Nevertheless, although the incidence of the disease in this hospital has fallen from $10.8 \%$ to $0.7 \%$ to $0.2 \%$ in the three periods $1919-20,1946-50$, and 1957, the incidence of carditis in each period is $56 \%, 59 \%$, and $52 \%$, as compared with Ceylon where only $35 \%$ of children with rheumatic manifestations showed evidence of cardiac disease.

\section{Clinical and Other Factors}

The clinical manifestations in children are similar to those in adults in Ceylon though there are certain differences. For instance, children do not appear to have repeated attacks of swelling in the joints or pain flitting from joint to joint. Those we see in hospital have perhaps two or three attacks of joint pain, and the knee, ankle and, though rarely, the elbow, appear to be the only joints affected. The episode is usually trivial and almost forgotten by the time the cardiac symptoms and signs manifest themselves. Moreover, the attacks subside rapidly in a few days. This contrasts with the picture seen in young adults: if they do give a history of joint pains they emphasize the severe nature of the attacks and their frequent recurrence over a period of years.

Cutaneous Manifestations. These are extremely rare in this country. During the last five years we can recall only three cases in this hospital in which subcutaneous nodules were present. It is amusing to see students searching for skin manifestations in the dark skinned children in this country. They are not seen even in the lighter skinned children of Ceylon. One of the rare examples of subcutaneous nodules is shown in Fig. 1.

TABLE 2

INCIDENCE OF RHEUMATIC DISEASE IN FOUR UNITS

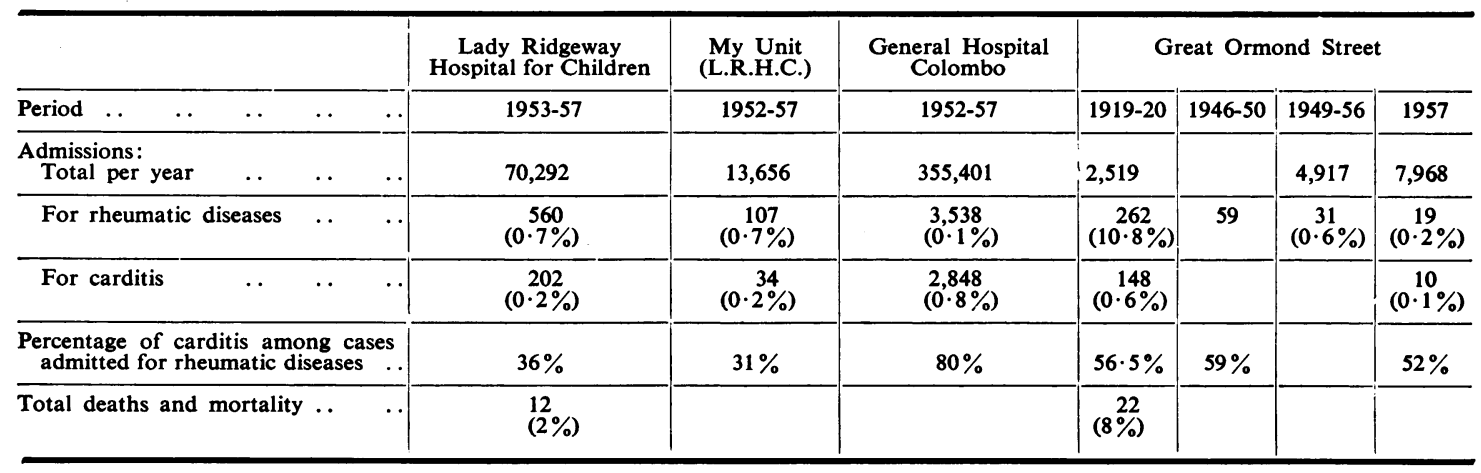




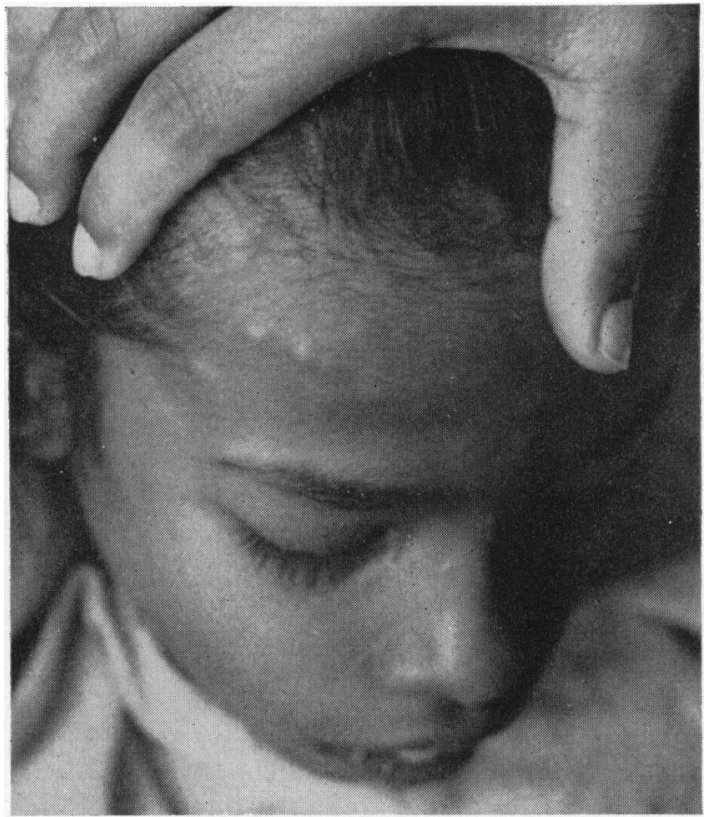

Fig. 1.-Subcutaneous nodules in a coloured child.

Cardiac Manifestations. Although only $0.2 \%$ of the total admissions to the Children's Hospital during the five-year period showed cardiac manifestations, it is interesting that only about $30 \%$ of those with rheumatic infection showed some cardiac lesions in contrast to the incidence of $80 \%$ seen in adults. The commonest lesion is mitral stenosis, which accounts for about $80 \%$ of the lesions seen in children. Aortic lesions by themselves are very rare in children, only one child with such lesions being seen in five years in my unit. A combined lesion is sometimes seen, and, extremely rarely, an isolated pericardial effusion.

Chorea. Chorea is a very uncommon manifestation of rheumatism in Ceylon. Out of 560 children there were only $13(0.2 \%)$ cases of chorea during the five-year period. This is a very striking contrast to the incidence seen in the temperate climate. For instance, in The Hospital for Sick Children, Great Ormond Street, in 1919-20 the incidence was $62 \%$ among 262 children and in 1946-50 39\% among 59 children. Chorea is also very rarely seen in the adult in Ceylon and equally rarely does the adult give a history of chorea in childhood.

Age Incidence. Only children under 12 years of age are admitted to the Children's Hospital. The disease is seldom or never seen in the toddler or in the child under 8 years of age, and most of the cases seen in the hospital are nearer 12 .

Economic Considerations. Rheumatic infection appears to be common in children of the poorer classes in the towns: labourers, artisans and traders. It is seldom seen in the village population. It is perhaps true that the village population is not so readily attracted to the hospitals as the town dweller, but with easier facilities for travel in recent years the hospital does draw a very large number of children from the rural areas. The impression gained is that the incidence is low in the rural areas and higher among the poorer people in the towns, while among the upper and middle classes in the towns it is distinctly uncommon. I have seen only four cases among 3,000 patients in private practice during the last 10 years. I believe that this is so even among the adult population.

Effect of Malnutrition. In a country like Ceylon where malnutrition is rife, and seen particularly in hospital practice, one would expect a serious infection like rheumatic infection to take a heavy toll. However, manifestations of rheumatic infection are conspicuous by their absence in the large numbers of malnourished children we come across daily.

\section{Conclusions}

Rheumatic fever appears to run a mild course in childhood in Ceylon.

The most common age of occurrence is in late childhood, from about 9 to 12 years.

Cardiac complications in childhood are much less common than in temperate climates and appear in a later age group, in early adult life.

The mortality in childhood is less than in England.

Cutaneous signs are very rarely seen.

Chorea is extremely rare in children in Ceylon.

REFERENCES

Cox, P. J. N. and Schlesinger, B. E. (1955). Paper read at Royal

Society of Medicine on May 25, 1955. Gt Ormond Str. J., No. 11 , p. 38 .

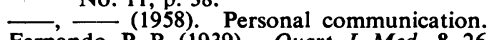

Fernando, P. B. (1939). Quart. J. Med., 8, 261. 